\title{
REPLY TO LETTER TO EDITOR: EFFECTS OF EXERCISE TYPE AND INTENSITY ON VISFATIN AND THE METABOLIC SYNDROME IN OBESITY
}

Jang-kyu Lee' (ID

(Physiologist)

1. Dankook University, College of Sports Science, Department of Exercise Prescription and Rehabilitation, Cheonan-si, Republic of Korea.

\section{Correspondence}

Jang-Kyu Lee

Dankook University, College of Sports Science, Department of Exercise Prescription and Rehabilitation. 119 Dandaero, Dongnam-gu, Cheonan-si, Chungchenongnam-do, Korea. kyu1216@hanmail.net.

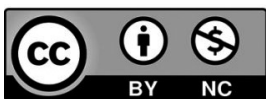

\section{Thanks for your comments}

First, time means pre-test ( 0 week) and post-test (8 week) as an independent variable.

Second, although not described in this paper, exercise time was quantified, and results agreed with your opinion. That is, the higher the intensity of the exercise, the shorter the exercise time, and the lower the intensity of the exercise, the longer the exercise time. However, the same amount of exercise was applied based on calorie consumption.

Therefore, in this paper, the effect of the types and intensity of exercise on visfatin and the metabolic syndrome in obesity was verified by making the amount of exercise the same based on calorie consumption.

The author declare no potential conflict of interest related to this article 